observations emphasise the importance of monitoring patients' inhalation technique, even when using attachments which claim to diminish the need for good coordination.

\section{Christine E Bucknal}

Centre for Respiratory

Investigation,

Royal Infirmary,
Glasgow, G4 OSF first aiders whom we teach and examine. Sports medicine enthusiasts, those in the British Association of Immediate Care Schemes, and those working with the first aid associations provide a reservoir of doctors with a special interest in first aid who would be prepared to pass on some of their expertise to colleagues at both undergraduate and postgraduate levels.

C C SMITH

Thatcham, Berks

Poor management of unconscious rugby player watched by millions

SIR,-Mr Goddard (21 April, p 1229) raises the importance of the care of an unconscious casualty on the rugby field, but I disagree with some of his observations.

I believe that Gallion was correctly treated given that there was a chance that his spine was fractured. Since he was breathing, his chances of an uncomplicated recovery were greater if he was left lying on his back. I agree that most unconscious people should be placed in the recovery position, but the exception is when there is a coexistent spinal fracture. In this case the diagnosis of such a fracture was rightly assumed until it could be proved otherwise. The only first aid he required was removal of the ubiquitous chewing gum and gumshield. The fact that he survived on his back for so long proved that his airway was adequate. Had he started to vomit or choke then he should have been "log rolled" into the recovery position.

I agree that all players and referees should know enough first aid to know what to do and not to do. Television commentators should use any opportunity to tell the audience what is happening and why.

I too was disappointed by the way Gallion was removed from the field. He should have been lifted by a "scoop stretcher," which should then have been placed on an orthodox rigid stretcher. Only then should he have been carried off.

People who faint in the crowd can be carried off safely in the recovery position on an ordinary stretcher, but unfortunately we usually see them transported on their backs in danger of airway obstruction from their tongue or vomit.

P N PATERSON-Brown Honorary Medical Adviser to the Red Cross (Scotland)

Hawick

SIR,-A more basic issue is raised by $\mathrm{Mr} \mathrm{N}$ Goddard (21 April, p 1229) than simply the immediate treatment of sports injuries. What training does a doctor have in first aid ? Must he rely on that learnt long ago in youth organisations or Combined Cadet Force?

Frequently we are asked by the St John Ambulance and British Red Cross Society to teach and examine would be first aiders. The more conscientious may read the first aid manual, but are we worthy of the thanks we receive from these voluntary societies? We should be as adept in placing casualties in the recovery position as we are in treating the underlying condition. Our knowledge of bandaging is acquired rather than taught, and we are dependent on the arrival of the ambulance to deal with fractures rather than attempting to immobilise a broken limb ourselves.

We should be at least as proficient as the conclusions that the deleted allele is not a norm occurring variant. Full details of the control group Sizes are in kilobases. used to establish this were not published, but 200 of the " 400 normal controls" were a series from this laboratory comprising 54 normal individuals and 146 with a variety of connective tissue disorders. These were all European, and none carried the deletion. The remaining members of the control group were also biased towards clinical conditions, and in this group a similar deletion was seen in a father and son with mild Ehlers-Danlos syndrome type II. Three of four cases reported by Dr Pope and others originated from India so it remained possibility that the deleted gene was a normal variant occurring with different frequencies in different racial groups. In this laboratory we have been interested in using polymorphic variants as genetic linkage markers for this gene so we examined a preliminary series of 39 immigrants of Indian or African origin. ${ }^{1}$ DNA was prepared from peripheral blood collected by colleagues from among staff and patients attending various non-orthopaedic outpatient clinics. Digestion with restriction endonucleases, electrophoresis, and blotting were carried out by standard procedures. Filters were hybridised to the ${ }^{32} \mathrm{P}$-labelled whole cosmid $\cos \mathrm{H}$ coll.

Three of 31 Indians and two of eight Africans were heterozygous for a deletion near the $3^{\prime}$ end of the gene apparently identical to that reported by Dr Pope and others (figure). It thus appears that the deleted gene is a fairly common allelic variant in these populations rather than a rare mutant. Further investigations in progress will establish accurate allele frequencies in these and other populations and, we predict, will show normal individuals homozygous for the deletion. The al(1)-like gene codes for a collagen important in cartilage synthesis and the deletion is probably beyond the $3^{\prime}$ end of the gene. ${ }^{2}$ It is therefore unlikely to affect expression of the gene either alone or in combination with other alleles. The frequency of this variant may be appreciably higher among cases of lethal osteogenesis imperfecta than in the parent populations. If so it could still be a useful linkage marker for the disease.

It is also possible, however, that this variant is not relevant to perinatal lethal oesteogenesis imperfecta and the association described by Dr Pope and others is coincidental. Until these two alternatives are distinguished we think it is premature to base estimates of recurrence risk, antenatal diagnosis, or decisions about termination on the segregation of this variant.

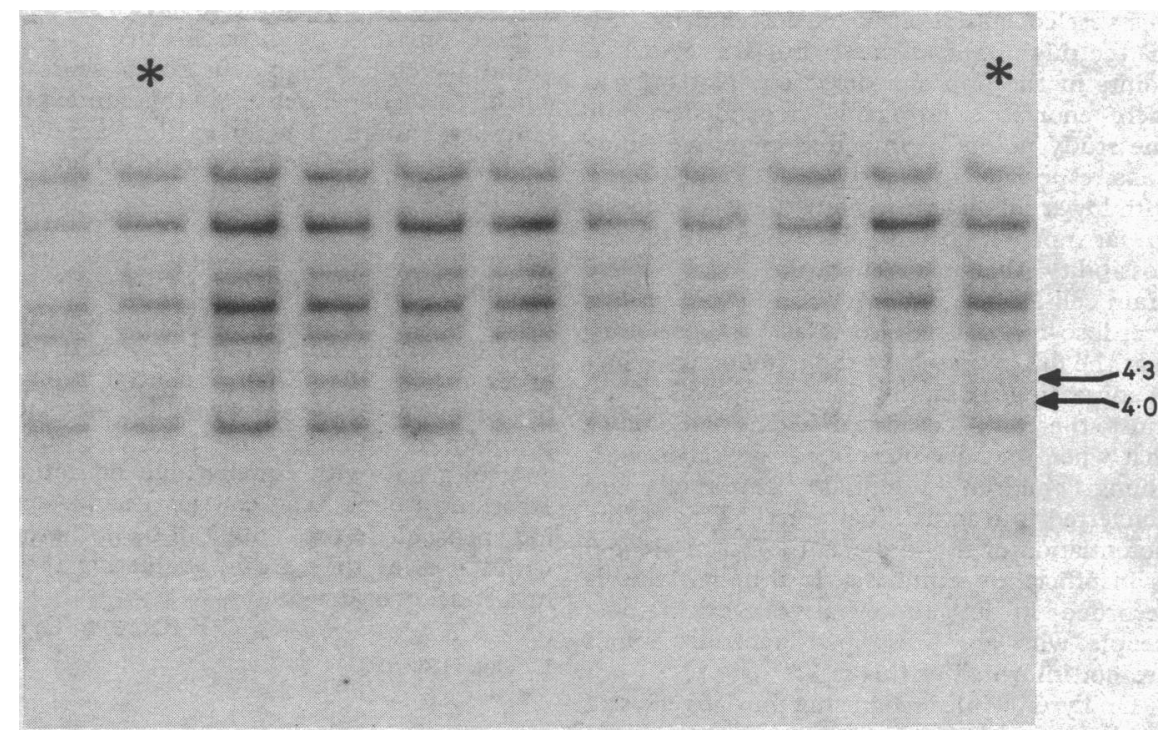

Eco R1 digests of DNA from eleven phenotypically normal Indian individuals probed with ${ }^{32} \mathrm{P}$ labelled cosmid. The two starred tracks demonstrate a deletion of approximately 300 base pairs.

Thanks are due to the several colleagues who cooperated in the collection of blood samples. This work was partly supported by grants from the Nuffield Foundation and the Rehabilitation and Medical Research Trust.

BRYAN SYKES

DONALD OGILvIE

Nuffield Department of Pathology,

John Radcliffe Hospital, 
'Sykes BC. A high frequency Hind III restriction site polymorphism within a collagen gene. Disease

Molymorphism within a collagen gene. Disease
"Cheah KSE quoted in Sykes BC. Collagen and inherited connective tissue disease. Nature 1983; 305:764.

***Dr Pope and Dr Nicholls reply below. -

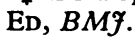

SIR,-As there was no indication that broad boned lethal osteogenesis imperfecta is more common in any particular racial group we considered the combined control samples we used were adequate. We had seen at least three affected Anglo-Saxon patients with the deletion, but no Anglo-Saxon control carried a similar change. The probability that three consecutively affected patients would show the deletion is greater than chance alone and would be at least $(1 / 400)^{3}$ - that is, $1 / 64000000$. If $\mathrm{Dr}$ Sykes and $\mathrm{Mr}$ Ogilvie's observation is confirmed, however, then a frequency of $10 \%$ among Asian Indians would increase the chance of three consecutive babies with osteogenesis imperfecta carrying the deletion to the much less impressive figure of $(1 / 10)^{3}$

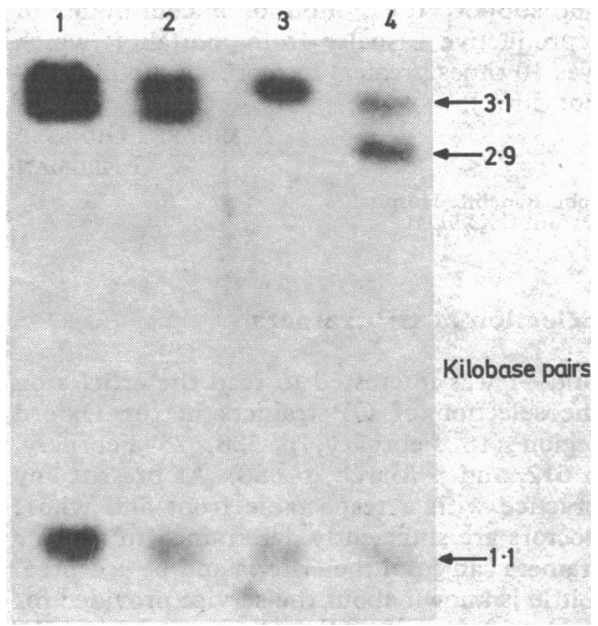

Double Eco $\mathrm{R} 1$ and Bam $\mathrm{H} 1$ digestions of DNA from patients with osteogenesis imperfecta congenita and control. The $4 \cdot 3 \mathrm{~kb}$ Eco Rl fragment shown in the figure of Dr Sykes and Dr Ogilvie is cleaved into $3.1 \mathrm{~kb}$ and $1.1 \mathrm{~kb}$ fragments. Similarly the $4.0 \mathrm{~kb}$ fragment becomes $2.9 \mathrm{~kb}$ and $1.1 \mathrm{~kb}$ respectively. Tracks 1,2 , and 4 show patients with osteogenesis imperfecta. Track 3 is a normal control. The pattern shown in track 4 is similar to that described in our earlier paper. Tracks 1 and 2 show variations in which the abnormal allele produces 3.0 and $1.1 \mathrm{~kb}$ fragments.

that is, $1 / 1000$ in that population. There are nevertheless several potential flaws in the argument.

Firstly, joint hypermobility and blue sclerae are common among Asian Indians so that perhaps collagen gene abnurmalities are also frequent. ${ }^{1}$ Their effects need not necessarily be disadvantageous in heterozygotes as the heterozygote parents in our study were to all intents and purposes clinically normal. Our evidence suggests that it is a combination of the 300 base pair deletion with another unidentified gene defect which may result in osteogenesis imperfecta. We obviously have no indication as to the frequency of the latter mutant in the general population.
Secondly, in our patients digestion with Eco $\mathrm{R} 1$, Bam $\mathrm{H1}$, and other enzymes ${ }^{2}$ has confirmed an actual deletion of a segment of DNA. ${ }^{2}$ We assume that Dr Sykes and Mr Ogilvie's studies are similar, although they illustrate only a single Eco R1 digestion. Although their patients show apparently clinically neutral changes there is no certainty that these are identical to our observations in osteogenesis imperfecta congenita. We already have evidence for at least two separate deletions in this disease group (figure), and others (relevant or irrelevant) are certainly possible. Cloning and sequencing of the deletion that we have observed will finally answer the speculation whether it lies within the collagen gene. Similar studies will also be required to assess the importance of Dr Sykes and Mr Ogilvie's observation.

F M POPE

A C Nicholls

Dermatology Research Group,

MRC Clinical Research Cen

' Beighton P, Grahame R, Bird H. Hypermobility of joints. Berlin: Springer-Verlag, 1983:23.

Pope FM, Weiss E, Nicholls AC. Collagen $\alpha 1$ (1)-like gene defects in Ehlers-Danlos syndrome and Dermatol 1983;80:324-5.

\section{Psychosis after cannabis abuse}

SIR,-We question the assertion by $\mathrm{Dr}$ M W P Carney and others (7 April, p 1047) that "Psychosis after abuse of cannabis is well recognised. ..."

Most published studies, including those cited by Dr Carney and others, are either anecdotal single case studies or unsystematic series. Altman and Evenson highlighted the pitfalls inherent in these types of study by showing that of 158 psychiatric admissions 38 were preceded by cannabis intake and 123 by watching a late night television movie. ${ }^{1}$ No attempt is made in such series to establish that "psychosis" is more common in cannabis users. They fail to show a statistically significant correlation between the two, let alone a causal link.

Such criticisms might partially be offset if the psychoses had enough common features to warrant the label of a clinical syndrome. A causal mechanism would then be possible (as in amphetamine psychosis). The published studies, however, including that of Dr Carney and others, describe a heterogeneous group of reactions with no clue to the cause.

Even assuming that there is an association between cannabis and psychiatric disturbance it is possible that in an established cannabis user a condition with hypomanic features might lead to an increased intake. We have observed two such patients recently, and an account of four others has been published. ${ }^{2}$

There are two valid reports of attempts to correlate cannabis use with mental illness. ${ }^{34}$ One study of longstanding users and matched controls found no significant differences between the groups in the incidence of psychiatric problems. ${ }^{3}$ The other study found a higher incidence of psychopathology in cannabis users, but this preceded the first use of the drug.

There is a worrying tendency for psychotic episodes in Afro-Caribbeans, especially Rastafarians, to be attributed to cannabis. This may lead the psychiatrist to overlook a treatable primary functional psychotic disorder or an acute psychotic reaction. ${ }^{5}$

We are concerned that the term "cannabis psychosis" has crept into medical reports without justification. We suggest that the methods used to show its existence are as valid as those used in the last century to establish "masturbation insanity."

Philip CARNey

MAURICE LIPSEDGE

Department of Psychiatry,

Guy's Hospital Medical School,

London SE1 9RT

'Altman H, Evenson RC. Marijuana use and subsetoms: a replication. Compr Psychiatry 1973;14:415-20.

${ }^{2}$ Harding T, Knight F. Marihuana-modified mania. Arch Gen Psychiatry 1973;29:635-7.

Halikas JA, Goodwin DW, Guze SB. Marihuana use and psychiatric illness. Arch Gen Psychiatry 1972; 27:162-5.

Beaubrun MH, Knight F. Psychiatric assessment of 30 chronic users of cannabis and 30

Am F Psychiatry 1973;130:309-11. mone Psychol Med 1981;11:289-302.

SIR,-I am pleased to see that British psychiatry is at last recognising psychosis after cannabis use. The experience of Dr M W P Carney and others is exactly that of most psychiatrists in the Caribbean.

Between March 1983 and March 1984 I saw five cases of psychosis following heavy use of cannabis in an island population of 6500. The patients were all men in their 20s. Two presented with violent manic bouts, and three had schizophreniform symptoms. All had normal premorbid personalities, and one had had a similar manic episode two years previously-again following a bout of heavy cannabis smoking. All the episodes resolved in under three weeks.

Such events are a normal part of psychiatry in the Caribbean, and I wonder why this condition is not recognised so readily in Britain. One possible explanation is the widespread home cultivation of Cannabis sativa L, particularly among Rastafarians. The cannabis here is therefore readily available in an unadulterated form giving a higher average dose than in Britain. This research should provide interesting material for the debate about cannabis legalisation.

M G Brook

Anguilla,

West Indies

\section{Psychiatry and violent offenders}

SIR,-Dr Richard Smith (28 January, p 310) points out that both prisoners and judges have inflated ideas about what psychiatry might achieve in treating the mentally abnormal offender. As an example of this point I recently had a prisoner who had referred himself for treatment.

The prisoner was a 29 year old single, unemployed man who was serving a three month sentence for assault. He came from a united but socially and emotionally deprived background; he had suffered from secondary enuresis until 15, and had often truanted from school. He joined the army at 17 and was often in trouble due to violence. He was eventually discharged from the army at 26 after assaulting and threatening to shoot an officer. For the past three years he has been unemployed, living rough, and abusing both alcohol and illicit drugs. He has frequently been convicted of violent crimes. On examining his mental state 